\title{
Esterification of Benzyl Alcohol with Acetic Acid over Mesoporous H-ZSM-5
}

\author{
Desy Tri Kusumaningtyas ${ }^{1}$, Didik Prasetyoko ${ }^{*}$, S. Suprapto ${ }^{1}$, Sugeng Triwahyono ${ }^{2}$, \\ Aishah Abdul Jalil ${ }^{2}$, Afifah Rosidah ${ }^{1}$
}

\begin{abstract}
${ }^{1}$ Department of Chemistry, Institut Teknologi Sepuluh Nopember, Surabaya 60111, Indonesia
¿Ibnu Sina Institute for Fundamental Science Studies, Universiti Teknologi Malaysia,
\end{abstract} Skudai, Johor Bahru 81310, Malaysia

Received: 21 ${ }^{\text {st }}$ November 2016; Revised: $1^{\text {st }}$ February 2017; Accepted: $18^{\text {th }}$ February 2017

\section{Abstract}

In this study, the performance of mesoporous ZSM-5 has been studied on the esterification of acetic acid (AA) with benzyl alcohol (BA). The mesoporous ZSM-5 catalyst has been synthesized with the variation of aging time i.e. 6,12 , and 24 hours at the same temperature, $70{ }^{\circ} \mathrm{C}$. The cation exchange of Na-ZSM-5 to H-ZSM-5 was performed before the catalytic activity test. The acidity type and amount of solids were determined by FT-IR spectroscopy using pyridine as a probe molecule. The characterization by pyridine adsorption showed that at a higher mesoporous surface area, the number of Lewis acid was increased. The highest mesoporous surface area, Lewis, and Brönsted acid sites were obtained by sample which has the lowest crystallinity, i.e. $255.78 \mathrm{~m}^{2} / \mathrm{g}, 0.2732 \mathrm{mmol} / \mathrm{g}$, and $0.20612 \mathrm{mmol} / \mathrm{g}$, respectively. Influence of mesoporous volume was studied on the catalytic activity of the mesoporous ZSM-5 in the esterification reaction. Conversion of acetic acid in the esterification reaction for samples of HZ-6, HZ-12, and HZ-24 were obtained by titration methods, i.e. 39.59, 36.39, and $32.90 \%$, respectively. Hence, the reaction temperature of $393 \mathrm{~K}$, molar ratio 1:4 (AA:BA) and catalyst loading $5 \%$ were selected as an optimum reaction parameters. Copyright (C) 2017 BCREC Group. All rights reserved

Keywords: Acetic Acid; Benzyl Alcohol; Esterification; Mesoporous; zeolite ZSM-5

How to Cite: Kusumaningtyas, D.T., Prasetyoko, D., Suprapto, Triwahyono, S., Jalil, A.A., Rosidah, A. (2017). Esterification of Benzyl Alcohol with Acetic Acid over Mesoporous H-ZSM-5. Bulletin of Chemical Reaction Engineering \& Catalysis, 12 (2): 243-250 (doi:10.9767/bcrec.12.2.806.243-250)

Permalink/DOI: http://dx.doi.org/10.9767/bcrec.12.2.806.243-250

\section{Introduction}

Zeolites are microporous crystalline aluminosilicate materials well known for their catalytic and adsorptive activity and selectivity. They also posses high surface area, high thermal and chemical stability and as such they have found application in a great number of processes ranging from petrochemical industry to environmental separations $[1,2]$. The activity

* Corresponding Author.

E-mail: didikp@chem.its.ac.id

Telp.: +6231-5943353; Fax.: +6231-5928314 of zeolites is determined by their intrinsic acidity, of both Lewis and Brönsted nature, or by active species (mostly metal ions or oxides) that can be introduced into the zeolite structure. However, the sole microporosity of zeolites, which plays a crucial role in their shape selectivity, can also be their biggest drawback [3,4]. The different reaction in esterification of acetic acid with benzyl alcohol using catalysts of $\mathrm{H} \beta$, HY, and H-ZSM-5 have also been observed [5]. The research showed that in addition to acidity, pore zeolite plays a very important role in the catalytic activity of ZSM-5. Molecules with diameters larger than the framework pore 
openings are restricted from entering and approaching the active sites. This imposes significant limitations in terms of the range of reactions that can be efficiently catalyzed.

Introduction of mesoporous into originally microporous zeolitic structures is one approach to obtaining the best of both worlds, i.e. creating materials with lower diffusion restrictions, which are able to host larger molecular species, while still retaining desired acidity of the active sites within the structure [4,5]. Such microporous/mesoporous zeolites are called hierarchical, a term which designates a zeolitic material with at least one additional level of porosity besides the intrinsic micropore system. The development of mesopority can be achieved by both synthetic and post-synthetic routes [68].

Hierarchical synthesis of ZSM-5 has been developed from kaolin as a source of silica and alumina, silicalite seed is added as to induced of ZSM-5 structure and CTABr for mesostructure [9]. Hierarchical ZSM-5 synthesized with temperature aging at $70{ }^{\circ} \mathrm{C}$ for 6,12 , and 24 hours. The results showed that the longer of aging time, the crystallinity of ZSM-5 was increased, but the area and volume of mesoporous tends to decrease. Furthermore, in this paper, we describe the correlation between acidity and crystallinity of mesoporous ZSM-5 synthesized from Bangka-Belitung's kaolin.

In present study, the performance of H-ZSM-5 mesoporous was evaluated in benzylation of acetic acid (AA) with benzyl alcohol (BA). The effect of pore size of zeolite H-ZSM-5 mesoporous on the catalytic activity was investigated. The detailed optimization of process parameters, such as: molar ratio and catalyst loading, were also carried out with aim to maximize AA conversion.

\section{Materials and Methods}

\subsection{Materials}

The raw material of kaolin were obtained from Bangka Belitung $\left(\mathrm{Al}_{4}\left(\mathrm{Si}_{4} \mathrm{O}_{10}\right)(\mathrm{OH})_{8}, 47 \%\right.$ $\mathrm{SiO}_{2}$ and $\left.22 \quad \% \quad \mathrm{Al}_{2} \mathrm{O}_{3}\right)$, sodium hydroxide ( $\mathrm{NaOH}$ pellet, Merck, $99 \%$ ), LUDOX $\left(\mathrm{SiO}_{2}, \mathrm{Al}-\right.$ drich, $30 \%$ ), and cetyltrimethylammoniumbromide (CTABr, $\mathrm{C}_{19} \mathrm{H}_{42} \mathrm{BrN}$, Merck, $97 \%$ ), ammonium acetate $\left(\mathrm{CH}_{3} \mathrm{COONH}_{4}\right.$, Merck, $\left.>98 \%\right)$, benzyl alcohol $\left(\mathrm{C}_{6} \mathrm{H}_{5} \mathrm{CH}_{2} \mathrm{OH}\right.$, Merck, $\left.99.5 \%\right)$, acetic acid glacial $\left(\mathrm{CH}_{3} \mathrm{COOH}, 100 \%\right)$, aqua demineralization (aqua DM), pyridine $\left(\mathrm{C}_{5} \mathrm{H}_{5} \mathrm{~N}\right.$, Merck, $99.9 \%$ ), potassium hydroxide $(\mathrm{KOH}$, pellet, $85 \%)$, oxalic acid $\left(\mathrm{H}_{2} \mathrm{C}_{2} \mathrm{O}_{4}\right.$, Merck, 99.5 $\%)$, ethanol $\left(\mathrm{C}_{2} \mathrm{H}_{6} \mathrm{O}\right.$, Merck, $\left.99.9 \%\right)$, n-hexane
$\left(\mathrm{C}_{6} \mathrm{H}_{14}\right.$, Merck, $\left.99 \%\right)$, and phenolptalein indicator $\left(\mathrm{C}_{20} \mathrm{H}_{14} \mathrm{O}_{4}\right.$, Merck).

\subsection{Synthesis of catalysts}

The mesoporous ZSM-5 has been synthesized [9]. It has been synthesized by hydrothermal method with two stages of crystallization. The mesoporous ZSM-5 were synthesized in a starting aluminosilicate gel with the components of $10 \mathrm{Na}_{2} \mathrm{O}: 100 \mathrm{SiO}_{2}: 2 \mathrm{Al}_{2} \mathrm{O}_{3}: 1800$ $\mathrm{H}_{2} \mathrm{O}$ mol ratio with a various aging time, i.e 6 , 12 and $24 \mathrm{~h}$ at $70{ }^{\circ} \mathrm{C}$, namely: A-6-70, A-12-70 and A-24-70. In this study, the cationic surfactant was added for mesostructure and seed silicalite to induce MFI structure.

Na-ZSM-5 mesoporous was weighed as much as 1.0 gram then was inserted into the three-neck-flask size $250 \mathrm{~mL}$, then, was added by $50 \mathrm{~mL}$ ammonium acetate $1 \mathrm{M}$. Subsequently, the mixture located within the round flask was connected with reflux and was heated to a temperature of $60{ }^{\circ} \mathrm{C}$, stirred for 3 hours at a speed of $500 \mathrm{rpm}$. Once completed, the mixture was filtered in a round flask with filter paper to obtain a precipitate. The precipitate was roasted prior to dry and then calcined at $550{ }^{\circ} \mathrm{C}$ for $1 \mathrm{~h}$ in $\mathrm{N}_{2}$ and $6 \mathrm{~h}$ in air to obtain H-ZSM-5 [10,11]. Further, the catalysts were known as HZ-6, HZ-12, and HZ-24.

\subsection{Catalyst Characterization}

Powder X-ray diffraction (XRD) patterns of the solids samples were collected on Philips X'pert XRD instrument with $\mathrm{Cu} \mathrm{Ka}$ radiation with a step size of $0.04^{\circ}$ and counting time of $10 \mathrm{~s}$. The samples were grinded in agate mortar before analysis. Data were recorded in the $2 \theta$ range of $5-50^{\circ}$. Nitrogen adsorption isotherms were measured at $77 \mathrm{~K}$ after pretreatment at $673 \mathrm{~K}$ for $4 \mathrm{~h}$ under vacuum. The total surface area was determined by the BET method, the total pore volume was obtained as the amount of nitrogen adsorbed at $P / P_{0}-0.99$, and the $t$-pot method was used to distinguish micropores from mesopores. Fourier transform infrared (FTIR) spectra of the samples were recorded on a Shimadzu spectrophotometer using the $\mathrm{KBr}$ pellet technique, in the range of 400-4000 $\mathrm{cm}^{-1}$. Spectra of pyridine adsorbed on the samples also were recorded on the same spectrophotometer for acidity study. Before measurement of pyridine adsorption, the samples were pressed to thin wafers (around 10 $\mathrm{mg} / \mathrm{cm}^{2}$ ) and placed into a sample holder. The sample discs were evacuated at $400{ }^{\circ} \mathrm{C}$ for $4 \mathrm{~h}$ in the $\mathrm{N}_{2}$ and cooled to room temperature. Then 2 drops of pyridine was exposed near the 
discs at room temperature. The adsorption was carried out at room temperature for $1 \mathrm{~h}$. The desorption procedure were conducted at $150{ }^{\circ} \mathrm{C}$ for $3 \mathrm{~h}$ in order to determine the acidity of Lewis and Brönsted acid sites by evaluating the amount of remaining adsorbed pyridine as temperature increases [12]. The concentrations of Brönsted (B) and Lewis (L) acid sites were calculated from the peak areas of adsorbed pyridine at around 1540 and $1450 \mathrm{~cm}^{-1}$, using $\mathrm{B}$ and $\mathrm{L}$ extinction coefficients $(\mathrm{k})$ of 1.88 and $1.42 \mathrm{~cm} . \mathrm{mmol}^{-1}$, respectively [13].

$$
\text { Amountof acid }(\mathrm{mmol} / \mathrm{g})=\frac{B \times l}{k \times w} 10^{-3}
$$

where, $\mathrm{B}=$ peak area of Lewis or Brönsted acid bond $\left(\mathrm{cm}^{-1}\right) ; \mathrm{L}=$ area of disk sample $\left(\mathrm{cm}^{2}\right)$; and $\mathrm{g}=$ weigh of disk sample $(\mathrm{g})$.

The scanning electron microscopy (SEM) images were obtained from SEM (ZEISS EVO MA 10). Dry samples were $\mathrm{Pd} / \mathrm{Au}$ coated prior to scanning. Concentration of $\mathrm{Si}$ and $\mathrm{Al}$ were determined by means of energy dispersive spectroscopy (EDX BRUKER $129 \mathrm{EV})$.

\subsection{Catalytic performance}

The synthesized catalysts were evaluated in benzylation of acetic acid with benzyl alcohol, which was carried out in a three-necked glass round bottom flask of $250 \mathrm{~mL}$ capacity equipped with a reflux condenser to prevent the escape of acetic acid, a thermometer and a magnetic stirrer. The flask was charged with acetic acid and benzyl alcohol both weighted sequentially, followed by the addition of the catalyst. Then, the system was heated up to desire temperature $(383 \mathrm{~K})$, the reaction was carried out for $3 \mathrm{~h}$, and finally the product was collected after removing the catalyst. For determination of free fatty acids conversion, $1 \mathrm{~g}$ sample was mixed with $5 \mathrm{~mL}$ of $96 \%$ ethanol and $5 \mathrm{~mL}$ n-hexane. Then the 3 drops of phenolphthalein indicator was added and titrated with $0.1 \mathrm{~N} \mathrm{KOH}$ solution. Previously, the $\mathrm{KOH}$ has been standardized with oxalic acid $0.1 \mathrm{~N}$. The titration was stopped when the color of the solution changes to pink which can last up to 30 seconds.

$$
\begin{aligned}
\% F F A & =\frac{V_{K O H} x N_{K O H} x M r_{K O H}}{\text { weight sample }} \\
\% \text { Conv } & =\frac{\% F F A_{\text {initial }}-\% F F A_{\text {final }} \times 100 \%}{\% F F A_{\text {final }}}
\end{aligned}
$$

\section{Results and Discussion}

\subsection{Characterization of catalyst}

The XRD patterns (Figure 1) shows that all the investigated samples preserved their MFI structure. However, the aging time influence the degree of crystallinity in the mesoporous samples. The rate of crystallization by aging more quickly than without aging [14] and the aging process serves to increase the nucleation, reducing the induction time and crystallization [15]. The variations in crystallinity of the mesoporous ZSM-5 (Table 1) was calculated based on the relative intensities of the reflection at $2 \theta$ of $23^{\circ}$, taking the crystallinity of the ZSM-5 commercial to be $100 \%$.

The isotherms of the nitrogen adsorptiondesorption of mesoporous samples are shown in

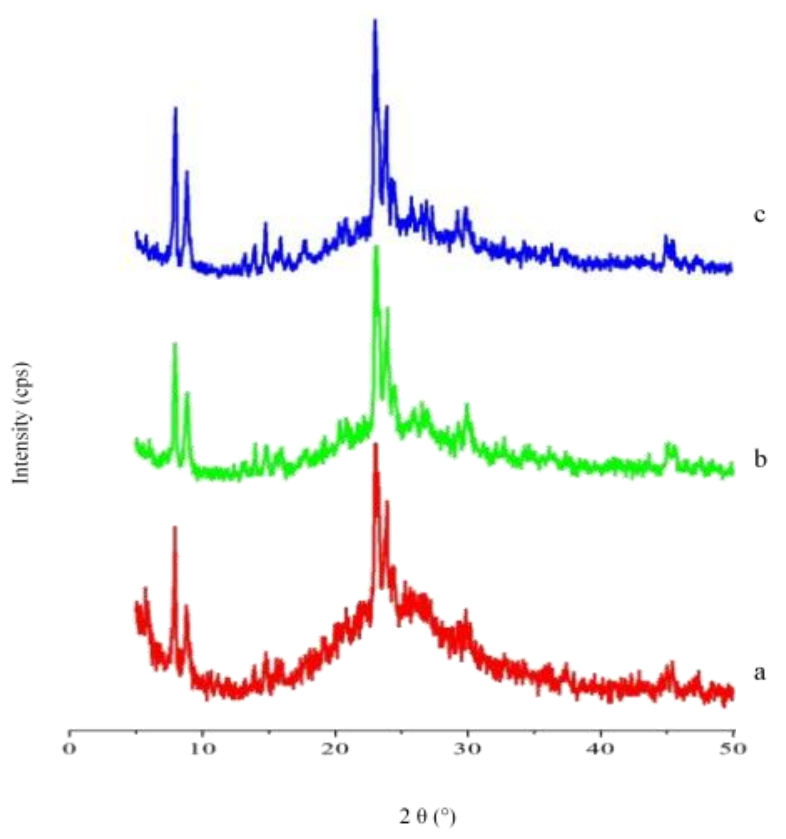

Figure 1. XRD patterns of the samples a. A-670, b. A-12-70, c. A-24-70

Table 1. The content of intensity and crystallinity of the samples

\begin{tabular}{cccc}
\hline Sample & $2 \theta$ & Intensity & Crystallinity (\%) \\
\hline ZSM-5 commercial & $23.14^{\circ}$ & 1813 & 100 \\
A-6-70 & $23.04^{\circ}$ & 218.68 & 12.06 \\
A-12-70 & $23.04^{\circ}$ & 423.44 & 23.36 \\
A-24-70 & $23.04^{\circ}$ & 501.95 & 27.69 \\
\hline
\end{tabular}


Figure 2. However, the mesoporous area, pore diameter, and mesoporous volume are shown in Table 2. All the isotherms showed type IV adsorption. As it can be seen from Table 2, the $S_{\text {BET, }} S_{\text {meso }}$ and $V_{\text {meso }}$ decrease with increasing ZSM-5 crystallinity. This phenomenon indicates that the crystallization of ZSM-5 occurs in the core of the mesophase particles, so that amorphous silica that acts as an intermediate in the transformation of the mesoporous walls into ZSM-5, is precipitated on the ZSM-5 crystallites preventing the access of nitrogen into the pores [16].

The acidity was aimed to determine the amount of Lewis and Brönsted acid sites of the samples. Surface acidity analysis was performed using pyridine adsorption and was analyzed by infrared spectroscopy. The Lewis and Brönsted acid sites can be known if there is a peak between 1440-1460 $\mathrm{cm}^{-1}$ and 1545-1600 $\mathrm{cm}^{-1}$. The acidity of the sample H-ZSM-5 mesoporous shown in Figure 3. All samples have Lewis acid sites (peak appears at wavenumber of 1442) and Brönsted acid sites

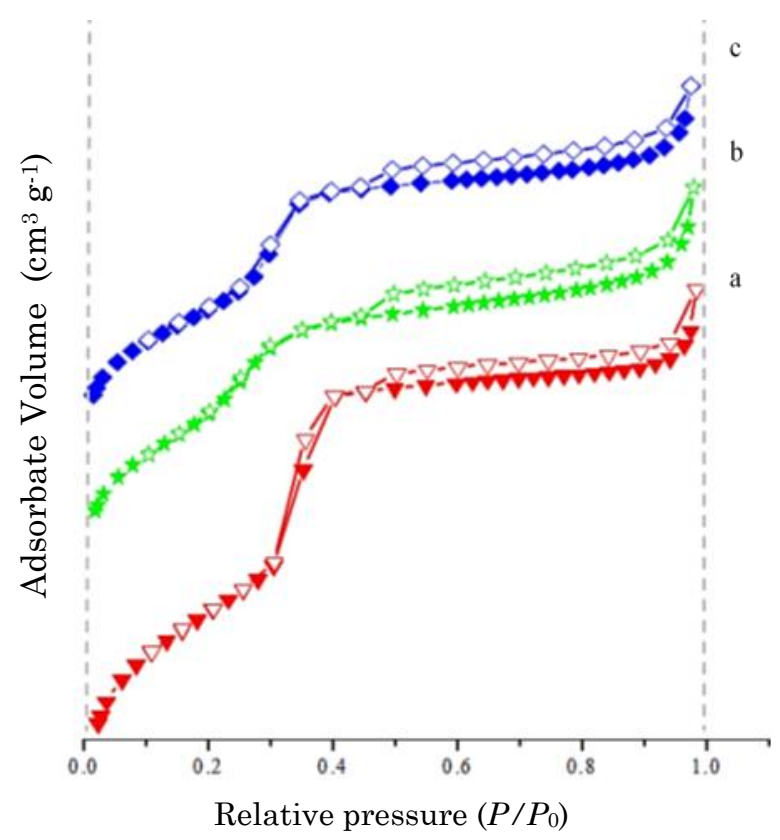

Figure 2. $\mathrm{N}_{2}$ adsorption-desorption Isotherm of samples a. A-6-70, b. A-12-70, c. A-24-70 (peak appears at wavenumber of 1550). Table 3 shows the amount of the Lewis acid and Brönsted acid sites of those samples. Lewis acid number of the A-6-70 samples is higher than others. The characterization by pyridine adsorption showed that at the higher crystallinity, the number of Lewis acid and Brönsted acid sites were decreased.

In this study, the A-12-70 catalyst has been selected to be observed its morphology and mapping (distribution) of the elements contained using instrument SEM-EDX. The observation of the surface of the catalyst is shown in Figures 4-5. In Figure 4 shows the morphology of the crystal-shaped beam. The results of SEM characterization were also obtained an average particle size of approximately $1 \mu(1000 \mathrm{~nm})$. The distribution of the elements contained in the A-12-70 catalyst is shown in Figure 5. The Figure 5a shows that the elements of $\mathrm{Na}, \mathrm{Si}, \mathrm{Al}$, and $\mathrm{O}$ were spread evenly on the catalyst and Figure 5b shows the EDX spectrum of catalyst.

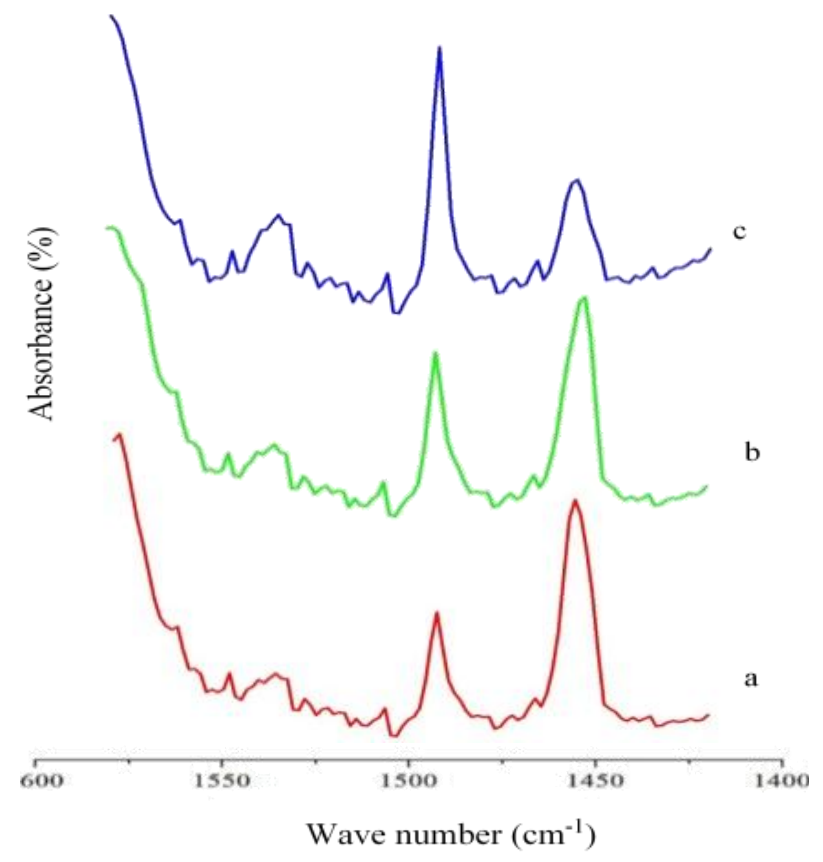

Figure 3. FTIR-Pyridine Spectra, a. A-6-70, b. A-12-70, c. A-24-70

Table 2. Textural properties of mesoporous ZSM-5

\begin{tabular}{ccccc}
\hline Sample & $S_{\text {BET }}\left(\mathrm{m}^{2} / \mathrm{g}\right)$ & $S_{\text {meso }}\left(\mathrm{m}^{2} / \mathrm{g}\right)$ & $V_{\text {meso }}\left(\mathrm{cm}^{3 / \mathrm{g}}\right)$ & $D_{\text {meso }}(\mathrm{nm})$ \\
\hline A-6-70 & 816.96 & 255.78 & 0.31 & 3.84 \\
A-12-70 & 709.45 & 120.86 & 0.22 & 3.83 \\
A-24-70 & 696.64 & 88.48 & 0.18 & 3.84 \\
\hline
\end{tabular}




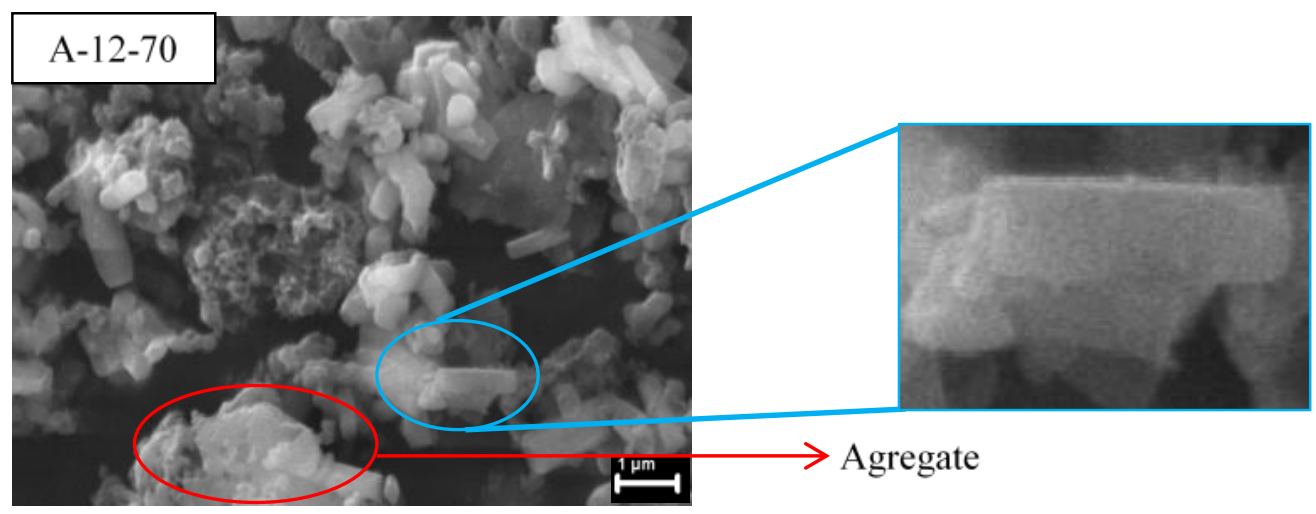

Figure 4. A-12-70 morphology using SEM
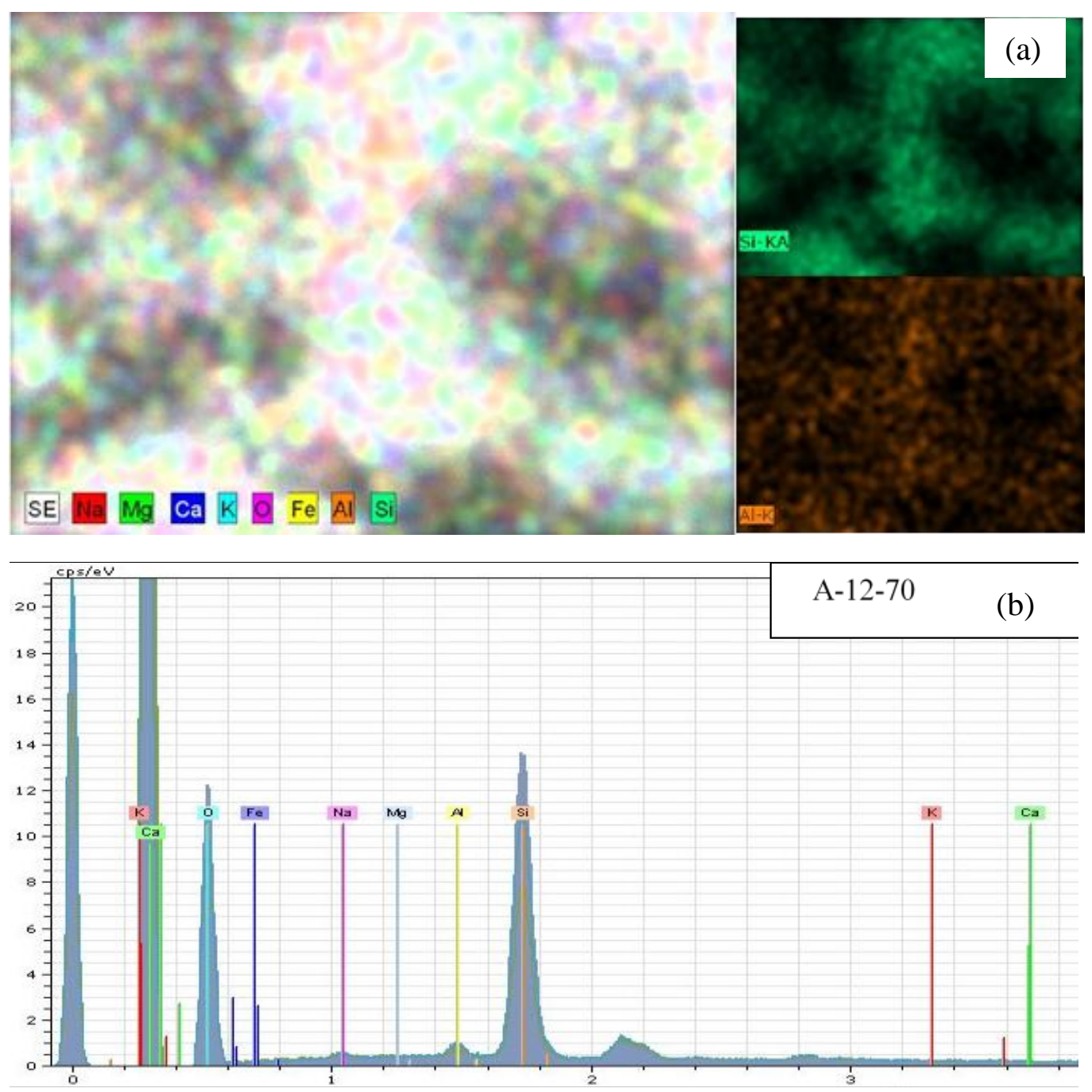

Figure 5. Mapping of A-12-70 catalyst (a) and EDX spectrum of A-12-70 (b)

Table 3. The amount of Lewis and Brønsted acid

\begin{tabular}{ccccc}
\hline Sample & $\begin{array}{c}\text { Surface area } \\
\left(\mathrm{m}^{2} / \mathrm{g}\right)\end{array}$ & $\begin{array}{c}\text { Crystallinity } \\
(\%)\end{array}$ & $\begin{array}{c}\text { Amount of Lewis } \\
\text { acid sites }(\mathrm{mmol} / \mathrm{g})\end{array}$ & $\begin{array}{c}\text { Amount of Brönsted } \\
\text { acid sites (mmol/g) }\end{array}$ \\
\hline A-6-70 & 255.78 & 12.06 & 0.27322 & 0.20612 \\
A-12-70 & 120.86 & 23.36 & 0.19075 & 0.18898 \\
A-24-70 & 88.48 & 27.69 & 0.08713 & 0.30956 \\
\hline
\end{tabular}




\subsection{Catalytic activity}

\subsubsection{Effect of catalyst properties on benzyla-} tion

Initial experiments were carried at $383 \mathrm{~K}$, 1:4 (AA to BA) molar ratio, catalyst loading of 5 $\%$ (wt.\% of AA), and reaction time of $3 \mathrm{~h}$. The HZ-6 was found to be potential catalyst with higher AA conversion of $37 \%$ which is attributed to the high acidity and pore volume of $0.31 \mathrm{~cm}^{3} \cdot \mathrm{g}^{-1}$ (Figure 6). Hence, the detailed optimization of process parameters was carried out for benzylation of AA with BA over HZ-6.

\subsubsection{Influence of molar ratio}

Benzylation of AA with BA was carried out by varying the molar ratio of AA to BA from 1:2 to 1:6 over HZ-6 to assess its effect on the catalytic activity. The effect of mole ratio over the conversion can be attributed with the occupancy of alcohols over the active sites and the

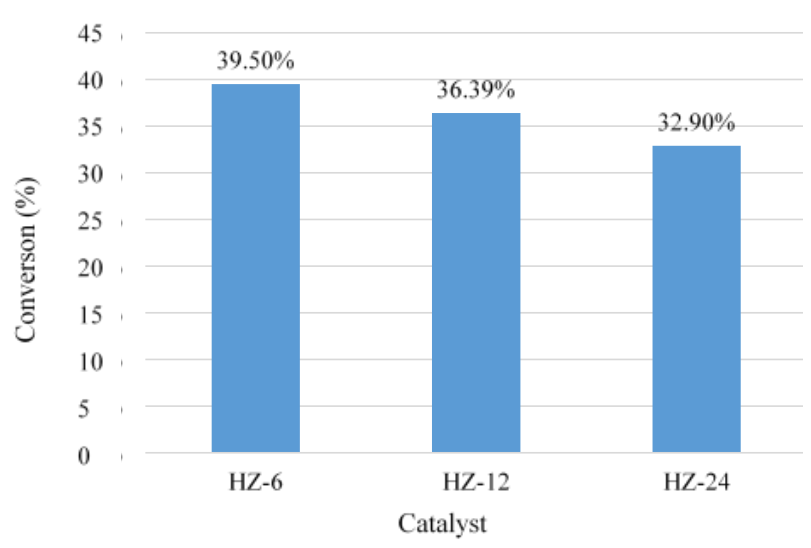

Figure 6. Benzylation of AA with BA over HZ6, HZ-12 and HZ-24 at molar ratio (AA:BA) of $1: 4$, catalyst loading of $5 \%$, reaction temperature of $383 \mathrm{~K}$ and reaction time of $3 \mathrm{~h}$

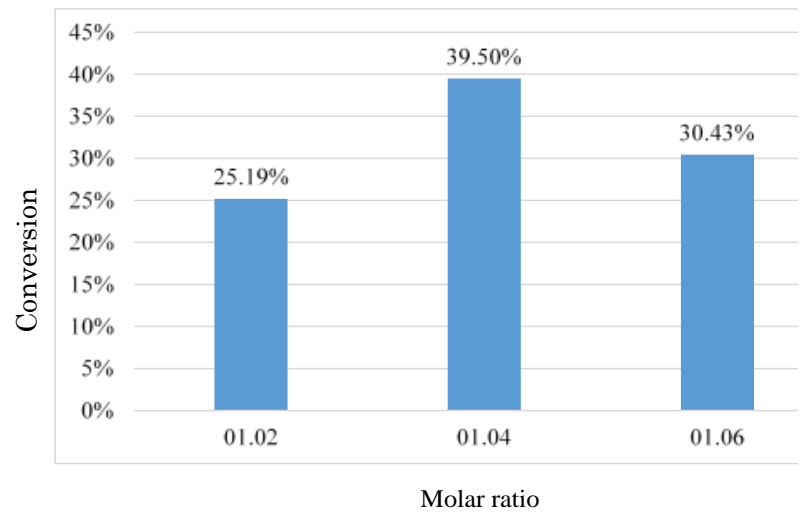

Figure 7. Influence of molar ratio on benzylation AA with BA over HZ-6 at catalyst loading $10 \%$, reaction temperature of $383 \mathrm{~K}$ and reaction time of $3 \mathrm{~h}$ availability of acid molecules for further esterification. The conversion of AA was found increase from 25 to $39 \%$ with an increase in reactant molar ratio from 1:2 to 1:4 (Figure 7). The conversion of AA significantly decreases its molar ratio from 1:4 to 1:6. Although the increase in alcohol content might be expected to increase the conversion, there might be dilution of acetic acid by increased alcohol contents, thereby preventing acetic acid adsorption on Brönsted acid sites [17]. Thus, all the further reactions were performed with a molar ratio (AA:BA) of 1:4.

\subsubsection{Influence of catalyst loading}

The effect of catalyst loading on the reaction was evaluated by varying the catalyst from 2.5 to $10 \%$ (wt.\% of AA). The AA conversion was found increasing from 32 to $37 \%$ with increase in catalyst loading from 2.5 to $5 \%$ (Figure 8). Increasing conversion with increase in the catalyst amount is due to the availability of large surface area, which favors the dispersion of more active species. Therefore, accessibility of the large molecule of the reactant to the catalyst active site is favored [17]. Further increase in catalyst loading, the AA conversion was found to be decreased. The $5 \%$ catalyst loading was observed to be optimum with AA conversion of $37 \%$.

\subsection{Mechanism for benzylation reaction}

The catalytic mechanism for synthesis of benzyl acetate by benzylation of AA with BA is proposed in Scheme 1. The reaction mechanism follows Fischer esterification involving several steps: starts with adsorption of AA on Brönsted acid sites present on the catalyst surface,

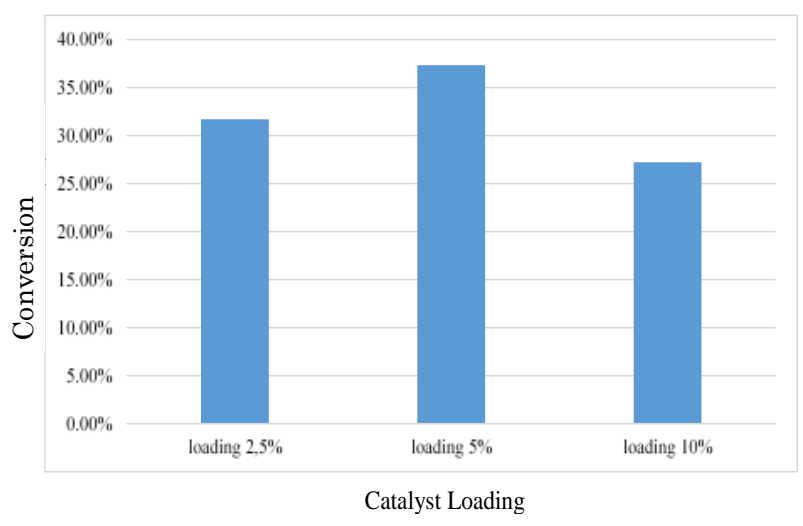

Figure 8. Influence of catalyst loading on benzylation AA with BA over HZ-6 at molar ratio $1: 4$, reaction temperature of $383 \mathrm{~K}$ and reaction time of $3 \mathrm{~h}$ 
forming an intermediate of protonated AA, which increases the electrophilicity of carbonyl carbon $[18,19]$. The H-ZSM-5 mesoporous catalyst facilitates the protonation of the carbonyl oxygen atom, due to large pore volume, which eliminates steric hindrances among framework and substituted groups. Nucleophilic oxygen atom from BA attracts the carbonyl carbon which forms an oxonium ion. The transfer of proton in an oxonium ion leads to formation of a new oxonium ion, with the losing molecule of water from last oxonium ion and followed by deprotonation forms the benzyl acetate, with the regeneration acid site on the surface of catalyst (Scheme 1).

\section{Conclusions}

Mesoporous ZSM-5 has been successfully synthesized from kaolin Bangka Belitung and colloidal silicate as aluminum and silicon source. Characterization using XRD results showed that the degree of crystallinity decreases with increasing mesopority. Nitrogen adsorption-desorption results showed that the longer of aging time, the surface area, and
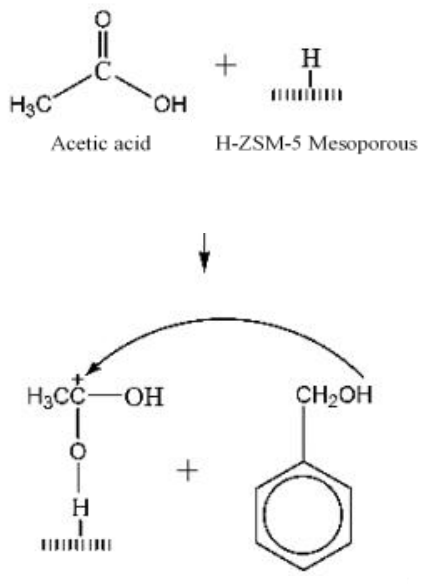

Benzyl alcohol

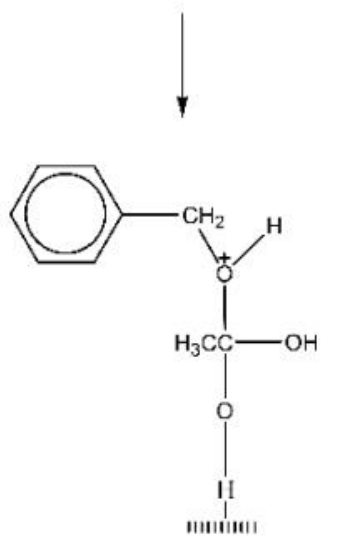

volume of mesoporous tends to decrease. Characterization by pyridine adsorption showed that the higher crystallinity, the number of Lewis acid sites were decreased. The highest mesoporous surface area and Lewis acid sites was obtained by sample which have a lowest crystallinity, i.e. $255.78 \mathrm{~m}^{2} / \mathrm{g}$ and 0.2732 $\mathrm{mmol} / \mathrm{g}$, respectively. The benzylation of acetic acid (AA) with benzyl alcohol (BA) has been carried out over zeolites H-ZSM-5 (HZ-6, HZ-12 and HZ-24). The AA conversion was in the order of HZ-6 > HZ $12>$ HZ-24. This micro/meso-HZSM-5 can be regarded as promising heterogeneous acid catalyst to improve the selectivity of desired monobenzylated product in aromatic benzylation and has potential application for chemical and pharmaceutical industry.

\section{Acknowledgement}

The authors would like to acknowledge the Ministry of Research and Higher Education, Indonesia, under "PUPT" research grant No. 003246.18/IT2.11/PN.08/2016.
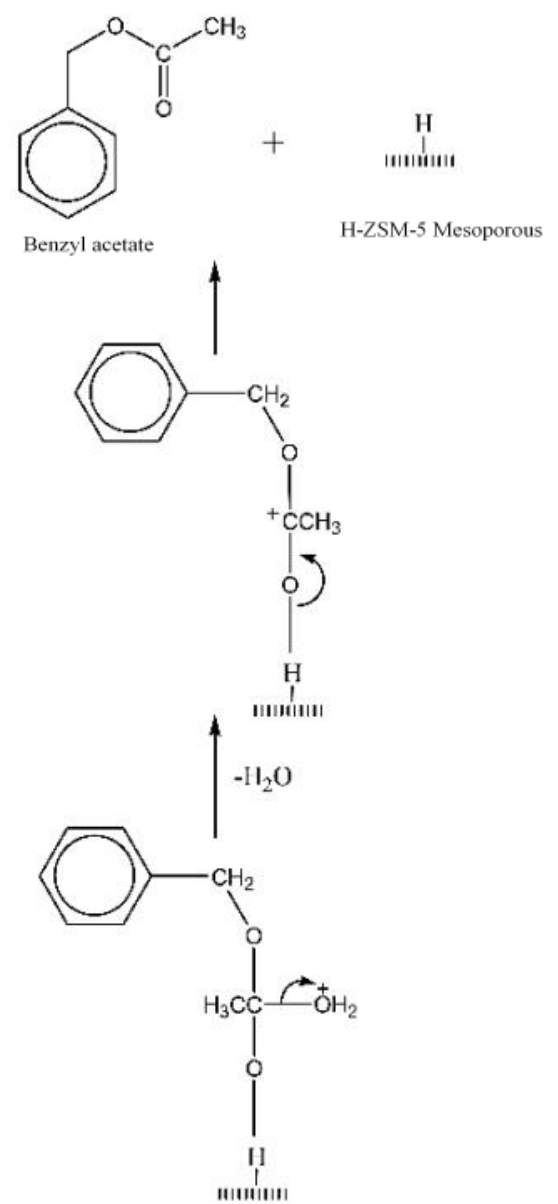

Scheme 1. Possible reaction mechanism for the benzylation of AA with BA over H-ZSM-5 mesoporous [5] 


\section{References}

[1] Vermeiren, W., Gilson, J.P. (2009). Impact of Zeolites on the Petroleum and Petrochemical Industry. Topics in Catalysis, 52: 1131-1161.

[2] Panagiotis, M. (2011). Application of Natural Zeolites in Environmental Remediation: A Short Review. Microporous Mesoporous Material, 144: 15-18.

[3] van Donk, S., Janssen, A.H., Bitter, J.H., de Jong, K.P. Generation, Characterization, and Impact of Mesopores in Zeolite Catalyst. Catalysis Reviews: Science and Engineering, 45: 297-319.

[4] Egeblad, K., Christensen, C.H., Kustova, M., Christensen, C.H. (2008). Templating Mesoporous Zeolites. Chemistry of Materials, 20: 946-960.

[5] Perez-Ramirez, J., Christensen, C.H., Egeblad, K., Christensend, C.H., Groen, J.C. (2008). Hierarchical Zeolites: Enhanced Utilisation of Microporous Crystals in Catalysis by Advances in Materials Design. Chemical Society Reviews, 37: 2530-2542.

[6] Xiao, F.S., Wang, L., Yin, C., Lin, K., Di, Y., Li, J., Xu, R., Su, D.S., Schlogl, R., Yokoi, T., Tatsumi, T. (2006). Catalytic Properties of Hierarchical Mesoporous Zeolites Templated with a Mixture of Small Organic Ammonium Salts and Mesoscale Cationic Polymers. Angewandte Chemie International Edition, 45: 3090-3093.

[7] Zhao, J., Hua, Z., Liu, Z., Li, Y., Guo, L., Bu, W., Cui, X., Ruan, M., Chen, H., Shi, J. (2009). Direct Fabrication of Mesoporous Zeolite with a Hollow Capsular Structure. Chemical Communications, 48: 7578-7580.

[8] Chal, R., Cacciaguerra, T., van Donk, S., Gérardin, C. (2010). Pseudomorphic Synthesis of Mesoporous Zeolite Y Crystals. Chemical Communications, 46: 7840-7842

[9] Hamid, A. (2015). Synthesis of Mesoporous ZSM-5 from Kaolin and Colloidal Silica with Two Step Crystallization : Influence of Temperature and Aging Time. Master Thesis, Kimia FMIPA, ITS Surabaya.

[10] Zein, Y.M. (2014). Biodiesel Production from Waste Palm Oil Catalyzed by Hierarchical ZSM-5 Supported Calcium Oxide. Master Thesis, Food Engineering and Bioprocess Technology, Asian Institute of Technology Thailand.
[11] Bariyah, U. (2014). Pengaruh Rasio $\mathrm{SiO}_{2} / \mathrm{Al}_{2} \mathrm{O}_{3}$ pada Sintesis ZSM-5 dan Aktivitas Katalitiknya untuk Reaksi Esterifikasi. Master Thesis, Kimia FMIPA, ITS Surabaya.

[12] Qoniah, I., Prasetyoko, D., Bahruji, H., Triwahyono, S., Jalil, A.A., Suprapto, Hartati, Purbaningtyas, T.E. (2015). Direct Synthesis of Mesoporous Aluminosilicates from Indonesian Kaolin Clay without Calcinations. Applied Clay Science 118: 290-294.

[13] Emeis, C.A. (1993). Determination of Integrated Molar Extinction Coefficients for Infrared Absorption Bands of Pyridine Adsorbed on Solid Acid Catalysts. Journal of Catalysis, 141: 347-354.

[14] Zhang, X., Wang, J., Liu, H., Liu, C., Yeung, K. (2003). Factors Affecting the Synthesis of Hetero-atom Zeolite FeZSM-5 Membrane. Separation and Purification Technology, 32: 151-158.

[15] Jihong, Y. (2007). Chapter 3 Synthesis of Zeolites. In: Čejka, Jiří, v. B., H., C., A., Ferdi, S. (Eds.). Studies in Surface Science and Catalysis. 168: 39-103.

[16] Goncalves, M.L., Dimitrov, L.D., Wallau, M., Urquieta-Gonzalez, E.A. (2006). Mesoporous ZSM-5 Synthesized by Simultaneous Mesostructuring and Crystallization of ZSM5 Nuclei. Scientific Bases for the Preparation of Heterogeneous Catalysts, E.M. Gaigneaux et al. (Editors), Elsevier, 323-330.

[17] Gokulakrishnan, N., Pandurangan, A., Sinha, P.K. (2007). Esterification of Acetic Acid with Propanol Isomers under Autogeneous Pressure : A Catalytic Study of Al-MCM-41 Molecular Sieves. Journal of Molecular Catalysis A: Chemical, 263: 55-61.

[18] Kirumakki, S.R., Nagaraju, N., Narayanan, S. (2004). A Comparative Esterification of Benzyl Alcohol with Acetic Acid over Zeolites HB, HY, and HZSM-5. Applied Catalysis A: General, 273: 1-9.

[19] Sawant, D.P., Vinu, A., Justus, J., Srinivasu, P., Halligudi, S.B. (2007). Catalytic Performances of Silicotungstic Acid/Zirconia Supported SBA-15 in an Esterification of Benzyl Alcohol with Acetic Acid. Journal of Molecular Catalysis A : Chemical, 276: 150-157

Selected and Revised Papers from The 2nd International Seminar on Chemistry (ISoC 2016) (Surabaya, 26-27 July 2016) (http://chem.its.ac.id/isoc-2016/) after Peer-reviewed by Scientific Committee of ISoC 2016 and Peer-Reviewers of BCREC journal 